\title{
Хива - жемчужина Востока и для третьего тысячелетия!
}

\author{
Г.Дурдиева, Хорезмская академия Мамуна, Хива, Узбекистан \\ К.Сабуров, Хорезмская академия Мамуна, Хива, Узбекистан \\ Б.Худайберганов, Хорезмская академия Мамуна, Хива, Узбекистан \\ 3.Рахимов, Хорезмская академия Мамуна, Хива, Узбекистан
}

В статье рассказывается об архитектурных памятниках Хивы, свидетельствующих о самобытной и богатой культуре узбекского народа, которая своими корнями уходит в далёкое прошлое. Город, насчитывающий 2500 лет, возник в античную эпоху в конце магистрального канала Хейканак (Полвон ёп), по которому ходили суда до самого города.

Ключевые слова: архитектура, реконструкция, реставрация, памятники, Хива, Хорезм.

Khiva is a Pearl of the East, Which is Also Relevant for the Third Millennium!

G. Durdieva, Khorezm Academy of Mamun, Khiva, Uzbekistan

K. Saburov, Khorezm Academy of Mamun, Khiva, Uzbekistan

B. Khudayberganov, Khorezm Academy of Mamun, Khiva, Uzbekistan

Z. Rakhimov, Khorezm Academy of Mamun, Khiva, Uzbekistan

The article describes the architectural monuments of Khiva show the original and rich culture of the Uzbek people, which has its roots in the distant past. The city originated in the ancient era at the end of the main canal Heikanak (Polvon ep) on which ships went to the city. It is 2,500 years old.

Keywords: architecture, reconstruction, restoration, monuments, Khiva, Khorezm.

Хива является одним из древнейших городов Центральной Азии и всего Востока. А Хивинский государственный историко-архитектурный музей-заповедник Ичан Кала (пл. 26 га) - один из крупнейших в СНГ. Это целостное архитектурное

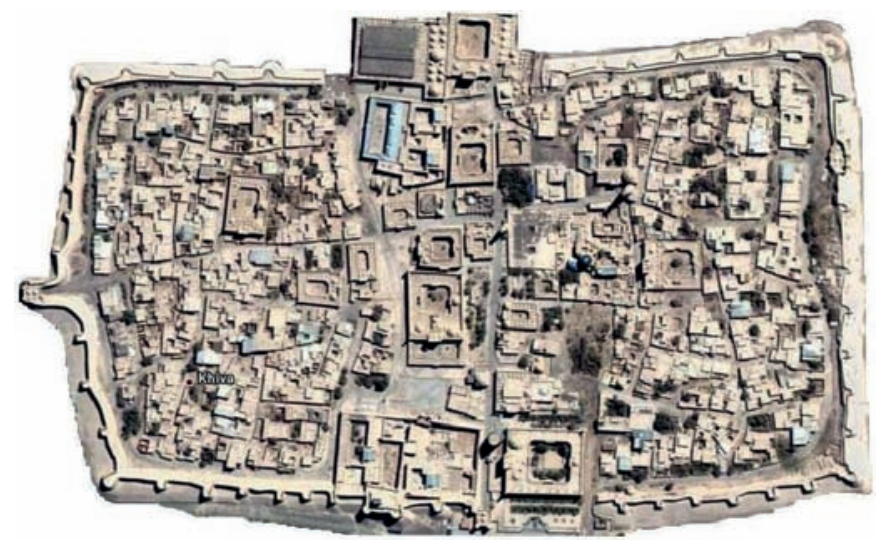

Рис. 1. Музей-заповедник Ичан-Кала (XVI век) сооружение, окружённое мощной крепостной стеной, с четырьмя воротами, в его пределах сосредоточены все основные памятники архитектуры (рис. 1).

Архитектурные памятники Хивы свидетельствуют о самобытной и богатой культуре узбекского народа, которая своими корнями уходит в далёкое прошлое. Город возник в античную эпоху в конце магистрального канала Хейканак (Полвон ёп) по которому ходили суда до самого города. В 1997 году во всемирном масштабе был отмечен его 2500-летний юбилей, но косвенные археологические материалы позволяют отодвинуть дату его возникновения ко времени появления в Хорезме священной книги зороастрийцев - Авесты, то есть к 2700 лет назад [1, с. 103].

Хива была столицей Южного Хорезма, а позднее, в XVI веке - всего Хорезма, центром его политической и культурной жизни. На протяжении своей многовековой истории Хива неоднократно переживала периоды подъёма и упадка, пока в XIX веке не достигла кульминационного расцвета. Сложившийся в этот период город в основной планировочной схеме сохранился до наших дней [2].

Хива богата историческими и архитектурными памятниками. Архитектурные памятники Хивы взяты под охрану ЮНЕСКО в 1990 году, и город по решению ЮНЕСКО включён в число 40 городов мира, чьи культурные наследия являются достоянием мировой цивилизации.

В последние годы на глазах меняется облик города, активизируется его социальное и культурное развитие. 0 н становится не только промышленном центром, но одним из крупных и перспективных центров развития отечественного и иностранного туризма в республике. С каждым годом увеличивается поток туристов в Хиву. Наличие в Хиве уникальных памятников вызывает к этому городу неослабевающий интерес со стороны отечественных, зарубежных туристов.

Архитектурные памятники являются частью культуры народа и человечества. Учитывая, какое огромное и неоценимое культурное богатство оставлено нам в наследство от предков, в Узбекистане принимаются соответствующие меры и затрачиваются материальное средства на их сохранение. Однако на сегодняшний день эти меры не достаточны. Памятники архитектуры многократно подвергались ремонту, на восстановление расходовались огромные средства. Иногда при восстановлении и реконструкции, без научного анализа и изучений допускаются грубейшие ошибки. 
В последние годы участились деформационные процессы в уникальных сооружениях из-за ухудшения природных условий и возрастания техногенной нагрузки из-за хозяйственной деятельности человека [3, с. 134]. Ряд сооружений находится в деформационно-напряжённом состоянии, следствием которого могут быть необратимые явления. В этом аспекте авральные методы восстановления сооружений и косметические ремонты отдельных элементов не всегда дают положительный результат с точки зрения устойчивости сооружений.

Отрицательное влияние времени на памятники архитектуры, к сожалению, неизбежно и необратимо. Однако памятники архитектуры не защищены не только от воздействия отрицательных факторов внешней среды, но они также не защищены и от техногенных воздействии и результатов хозяйственной деятельности человека.

Анализ литературных источников, архивных материалов и изучение в натуре архитектурных памятников Хивы показывают, что для этих сооружений достаточно хорошо изучены вопросы археологии, архитектуры, истории и искусствоведения, но, к сожалению, конструктивные особенности их сооружений, являющиеся несущие нагрузки, от которых главным образом зависит прочность, устойчивость, сейсмостойкость и долговечность сооружений, мало изучены [4, с. 156].

Поэтому по различным причинам (техногенное воздействие, уровень грунтовых вод, нарушение условий эксплуатации, сейсмические воздействия, термиты и др.) состояние архитектурных памятников сильно ухудшается. Для конкретных объектов отсутствуют документация и данные объёмно-планировочных и конструктивных решений, инженерно-геологических условий. Эти документы зачастую разрабатываются только в тех случаях, когда уникальные памятники архитектуры уже находятся в аварийном состоянии.

Для решения этих проблем учёными Хорезмской академии Мамуна ведётся мониторинг состояния памятников архитектуры Хорезма и разрабатываются методы защиты от влияния окружающей среды. Основной целью этих исследований является разработка методики комплексной оценки технического состояния исторических архитектурных памятников, по результатам которой разрабатывается система инженерного мониторинга за их состоянием и конкретные мероприятия по укреплению конструкции сооружений.

С течением длительного времени силовые факторы и внешние воздействия на здания и сооружения не уменьшаются, а составляющие основу памятника конструктивные материалы постепенно стареют. При этом происходит уменьшение первоначальной прочности материалов, и как следствие возникают длительные деформации конструкций. Накопление деформаций возрастает с ухудшением исторически сложившиеся природной среды, что постепенно приводит к локальным разрушениям, а иногда - и к полной потери устойчивости этих конструкций. В этой ситуации очень важно правильно оценить фактическое состояние объекта, выявить причины, отрицательно влияющие на прочность материала, и произвести их восстановление.

Для решения этих проблем необходимо рассмотреть вопросы прочности, устойчивости и технологию возведения монументальных памятников архитектуры, проанализировать причины ухудшения их состояния и предложить современные методы усиления и восстановления (рис. 2).

В процессе решения этих проблем:

- составлен банк данных по архитектурным памятникам Хорезма и произведена классификация их по срокам строительства, значимости и техническому состоянию на основе визуальных и инструментальных наблюдений;
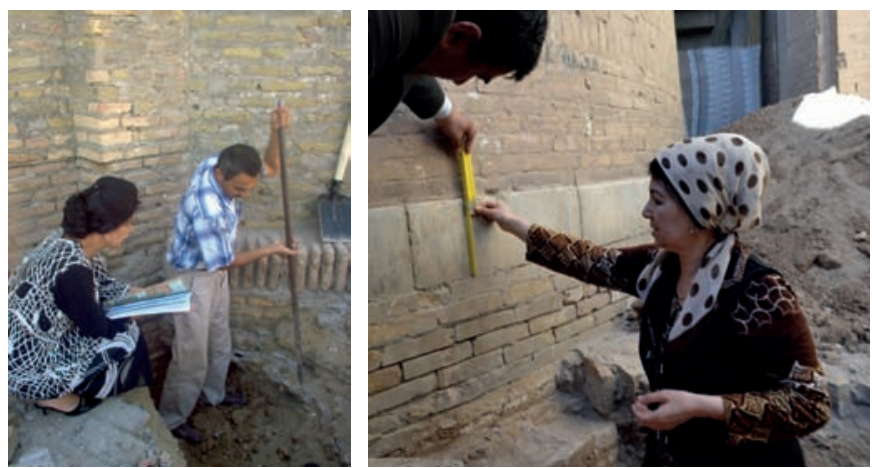

Рис. 2.Проведение авторами статьи экспериментальных исследований памятников архитектруры города Хивы. 2010-2020 годы

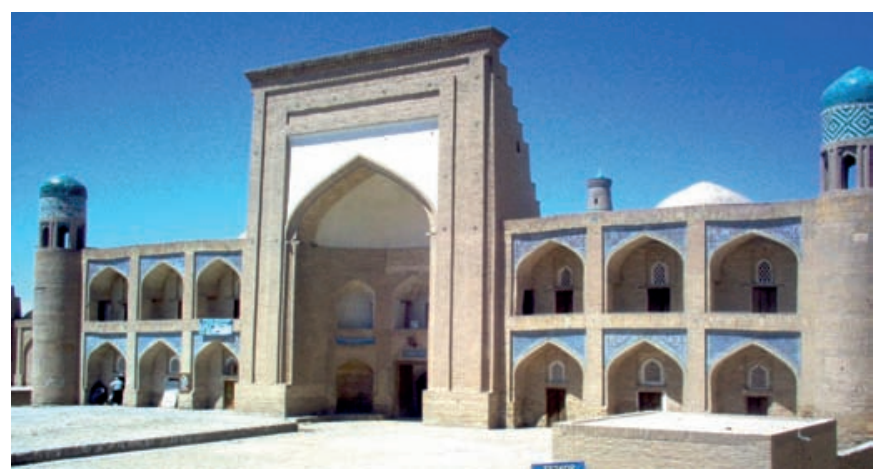

Рис. 3. Медресе Кутлуг-Мурад-Инака. 1804 год

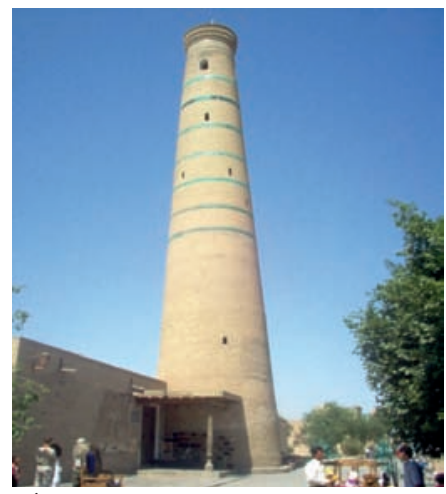

\section{a)}

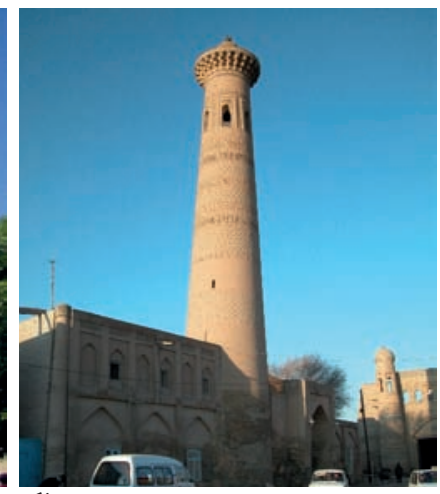

б)

Pис. 4. Минареты: а) Джума-Мачит. Х век; б) Саиднияз Шоликорбая. 1838 год 
- определено техническое состояние аварийных объектов - медресе Кутлуг-Мурад-Инака (рис. 3), мечеть и минарет Джума-Мачит (рис. 4), комплекс Саиднияз Шоликорбая (рис. 5);

- определены физико-механические и деформативные характеристики материалов конструкций стен, перекрытий и покрытия;

- организовано геодезическое, инженерно-геологическое и гидрогеологическое наблюдение за этими объектами;

- проведены измерения периода и частоты собственных колебаний минаретов и мечетей в натуре;

- установлены причины разрушения памятников архитектуры;

- разработаны мероприятия по обследованию и реконструкции памятников архитектуры.

По результатам исследований можно сделать следующие выводы.

- Архитектурные памятники необходимо укреплять так, чтобы повторные их усиление и реставрация потребовалась через максимально длительные сроки. При этом должно быть обеспечено высокое качество укрепительных и реставрационных работ. Во всех случаях следует считать, что проще устранить причину, вызывающую повреждения и увлажнения архитектурных памятников, чем многократно ликвидировать последствия производством усиления и ремонта.

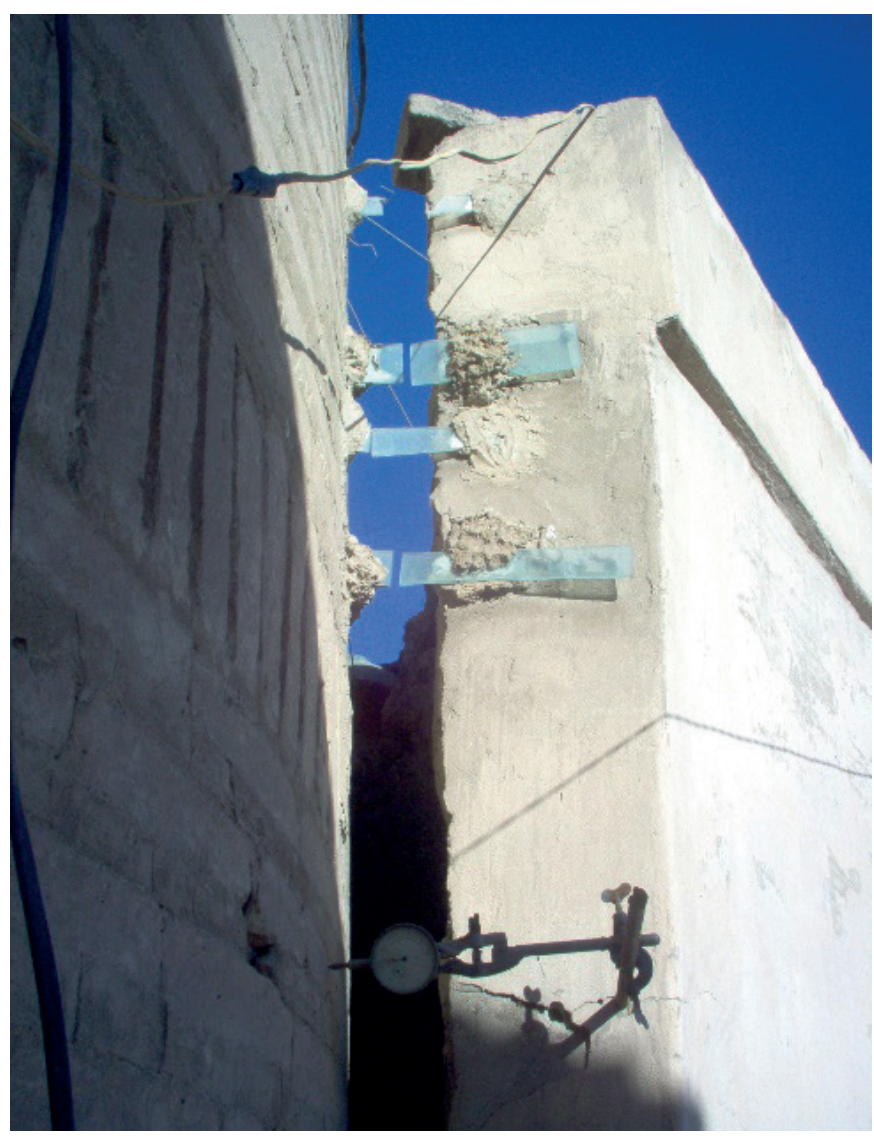

Pис. 5. Общий вид: разрыв стеклянных маяков у памятника Саиднияз Шоликорбая
- Проблема физического сохранения памятников архитектуры, подверженных различным видам воздействий, особенно остро проявляется при их реставрации. В Хорезме расположено более 250 историко-архитектурных памятников. На сегодняшний день различные виды деформаций отмечены более чем на 40\% памятников. Основными причинами деформаций памятников являются подъём уровня подземных вод из-за орошения и утечек воды из коммуникационных сетей, стока дождевых вод под фундаменты.

- Вследствие увеличения влажности происходит просадка лёссовидных грунтов основания. Просадка происходит неравномерно и, как следствие, в надземной части памятников образуются трещины и повреждения. На некоторых памятниках величина раскрытия трещин достигают 50 мм. Длина трещин доходит до нескольких метров (см. рис. 2). Проблема сохранения памятников усугубляется ещё и тем, что помимо деформации их основания, происходит интенсивное засоление стен памятников.

- Эпизодические исследования, проводимые по отдельным методикам и имеющие в своей основе различные подходы к определению геологических, геодезических, динамических характеристик и параметров памятников, не могут в полной мере решать вопросы охраны древних памятников. Только систематическое изучение полного спектра факторов, оказывающих отрицательное влияние и тщательный анализ изменения их во времени, сможет решить задачи прогнозирования дальнейших деформационных изменений.

В заключении необходимо отметить, что каждый памятник архитектуры, находящийся на территории Республики Узбекистан, в том числе памятники архитектуры Хивы, - это по существу, музеи под открытым небом. Все они подлежат охране и сохранению для потомков.

\section{Лumepamypa}

1. Асанов, А.А. Памятники архитектуры средневекового Хорезма / А.А. Асанов. - Ташкент, Фан, 1997.

2. Асанов, А.А. Памятники архитектуры и их конструкции / А.А. Асанов // Строительство и архитектура Узбекистана. - 1973. - № 7. - С. 18-21.

3. Холмурадов, Р.И. Конструкции архитектурных памятников Самарканда / Р. И. Холмурадов, А.3. Хасанов. - Самарканд, 2003.

4. Гендель, Э.М. Инженерные работы при реставрации памятников архитектуры / Э.М. Гендель. - М. : Стройиздат, 1980.

\section{References}

1. Asanov A.A. Pamyatniki arkhitektury srednevekovogo Khorezma [Monuments of architecture of medieval Khorezm]. Tashkent, Fan Publ., 1997.

2. Asanov A.A. Pamyatniki arkhitektury i ikh konstruktsii [Monuments of architecture and their constructions]. In: 
Stroitel'stvo i arkhitektura Uzbekistana [Construction and Architecture of Uzbekistan], 1973, no. 7, pp. 18-21.

3. Kholmuradov R.I., Khasanov A.Z. Konstruktsii arkhitekturnykh pamyatnikov Samarkanda [Engineering works in the restoration of architectural monuments]. Samarkand, 2003.
4. Gendel' E.M. Inzhenernye raboty pri restavratsii pamyatnikov arkhitektury [Engineering work in the restoration of architectural monuments]. Moscow, Stroiizdat Publ., 1980.

Дурдиева Гавхар Салаевна (Хива). Доктор архитектуры, старший научный сотрудник. Руководитель лаборатории Хорезмской академии Мамуна (220900, Республика Узбекистан, Хорезмская область, Хива, Марказ-1 Хорезмская академия Мамуна). Эл.почта: gavhar61@mail.ru.

Сабуров Кахрамон Уктамович (Хива). Аспирант лаборатории Хорезмской академии Мамуна (220900, Республика Узбекистан, Хорезмская область, Хива, Марказ-1 Хорезмская академия Мамуна). Эл.почта: saburov.kaxramon@mail.ru.

Худайберганов Бекзод Аллаберганович (Хива). Младший научный сотрудник Хорезмской академии Мамуна (220900, Республика Узбекистан, Хорезмская область, Хива, Марказ-1 Хорезмская академия Мамуна).Эл.почта: bek_88_88_uz@mail.ru.

Рахимов Зафар Хушнудович (Хива). Стажер Хорезмской академии Мамуна (220900, Республика Узбекистан, Хорезмская область, Хива, Марказ-1 Хорезмская академия Мамуна). Эл.почта: architector89@mail.ru.

Durdieva Gavkhar S. (Khiva). Doctor of Architecture, Senior Researcher. Head of thelaboratory at Khorezm Mamun Academy (Markaz-1, Khiva, Khorezm, Republic of Uzbekistan, 220900. Khorezm Mamun Academy). E-mail: gavhar61@mail.ru.

Saburov Kakhramon U. (Khiva). Postgraduate student of thelaboratory at Khorezm Mamun Academy (Markaz-1, Khiva, Khorezm, Republic of Uzbekistan, 220900. Khorezm Mamun Academy). E-mail: saburov.kaxramon@mail.ru.

Khudayberganov Bekzod A. (Khiva). Junior Researcher at Khorezm Mamun Academy (Markaz-1, Khiva, Khorezm, Republic of Uzbekistan, 220900. Khorezm Mamun Academy).E-mail: bek_88_88_uz@mail.ru.

Rakhimov Zafar K. (Khiva). Trainee at Khorezm Mamun Academy (Markaz-1, Khiva, Khorezm, Republic of Uzbekistan, 220900. Khorezm Mamun Academy). E-mail: architector89@mail.ru. 